\title{
Hidatidosis primaria de la musculatura de la pierna que simula un caso de fasceítis eosinofílica: Reporte de un caso*
}

\author{
Drs. FRANCISCO VENTURELLI M. ${ }^{1,2}$, PABLO BÓRQUEZ M. ${ }^{1,2}$, ALEXIS BAJAS P. ${ }^{3}$, FELIPE SILVA R. ${ }^{3}$
}

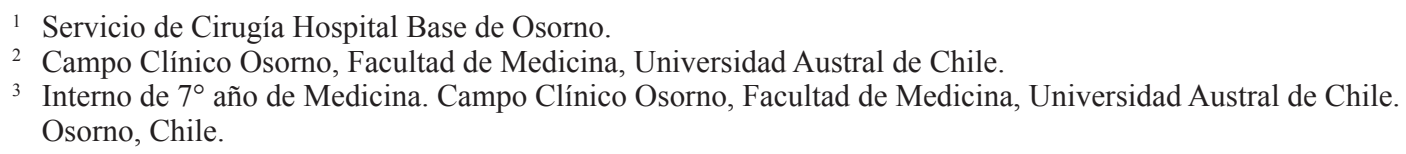

2 Campo Clínico Osorno, Facultad de Medicina, Universidad Austral de Chile.

${ }^{3}$ Interno de $7^{\circ}$ año de Medicina. Campo Clínico Osorno, Facultad de Medicina, Universidad Austral de Chile. Osorno, Chile.

\begin{abstract}
\section{Hydatid cyst of the soleus muscle. Report of one case}

Hydatid cysts may occasionally be confused with soft tissue tumors such as sarcomas. We report a 43 years old female living in a rural zone, presenting with a painful tumor in her left leg. A CAT scan showed the presence of a solid-cystic lesion in the left soleus muscle. A biopsy of the zone was informed as eosinophilic fasceitis and steroids were indicated. Two months later a new CAT scan showed that the lesion was increasing in size. An IgG for hydatidosis was positive. The patient was subjected to a cystectomy and the pathology report informed a hydatid cyst.
\end{abstract}

Key words: Hydatid cyst, fasciitis, soleus muscle.

\section{Resumen}

En nuestro país la hidatidosis sigue siendo un importante problema de salud pública. Generalmente compromete el hígado y el pulmón, sin embargo, se han reportado casos con compromiso de diversos órganos, como bazo, peritoneo y otras ubicaciones. Excepcionalmente puede presentarse como un tumor de partes blandas simulando un sarcoma u otro tumor. Presentamos un caso clínico de una paciente con hidatidosis de la musculatura de la pierna derecha tratado en el Hospital Base Osorno, que simuló una fasceítis eosinofílica; además se revisa el estado del arte de la hidatidosis muscular.

Palabras clave: Echinococcosis, muscular, tumores.

\section{Introducción}

La hidatidosis sigue siendo una zoonosis endémica, encontrando en algunas regiones hasta 40 casos nuevos al año'. Un 60 al $75 \%$ de los quistes hidatídicos se localizan en el hígado y el 15-30\% en el pulmón ${ }^{2,3}$. El restante 5-10\% se ubica en cavidad peritoneal, cerebro, miocardio, pericardio, riñón, retroperitoneo, hueso, partes blandas, bazo o mama ${ }^{3-6}$. El $1-5 \%$ se presentan a nivel musculoesquelético,

*Recibido el 9 de Junio de 2009 y aceptado para publicación el 2 de Octubre de 2009.

Correspondencia: Dr. Francisco Venturelli M.

Fax 56-064-253733

E-mail: icoventurelli@gmail.com 
siendo los músculos más frecuentemente afectados, el pectoral mayor, supraespinoso, bíceps braquial y muslo5.

La diseminación de esta enfermedad se explica porque después de la ingesta de los huevos del parásito adulto por parte del hombre (huésped intermediario), la oncósfera hidatídica es liberada en el estómago e intestino delgado atravesando la pared intestinal, llegando por vía porta al hígado. La diferencia de tamaño entre los capilares portales (20 micras), pulmonares (8 micras) y la oncosfera (30-36 micras) transforman a los 2 primeros en el primer y segundo filtro para el desarrollo de esta enfermedad. De sobrepasar ambas barreras, puede eventualmente llegar a desarrollarse en un órgano diferente como cerebro, peritoneo, u otro. La hidatidosis en la musculatura de la pierna es una entidad muy poco reportada. De hecho, al enfrentarnos a un tumor de partes blandas en esta localización, es difícil plantearlo como alternativa diagnóstica, haciéndonos pensar como primera posibilidad en otras lesiones.

Por otro lado, la fasceítis eosinofílica es un cuadro de muy baja incidencia, de etiología incierta, y que se caracteriza por un aumento del colágeno en la piel asociado a un infiltrado eosinofílico y linfocítico de la fascia muscular. Predomina en el sexo femenino entre los 40-50 años, se presenta con mayor frecuencia en extremidades inferiores y se manifiesta clínicamente por: induración de la piel, exudado, eritema y/o morfea. Puede asociarse a manifestaciones extracutáneas como artritis inflamatoria, rigidez articular, enfermedad pulmonar restrictiva y derrame pleural. En los exámenes el hemograma muestra eosinofilia, el factor reumatoideo y los anticuerpos antinucleares pueden estar elevados. Las enzimas

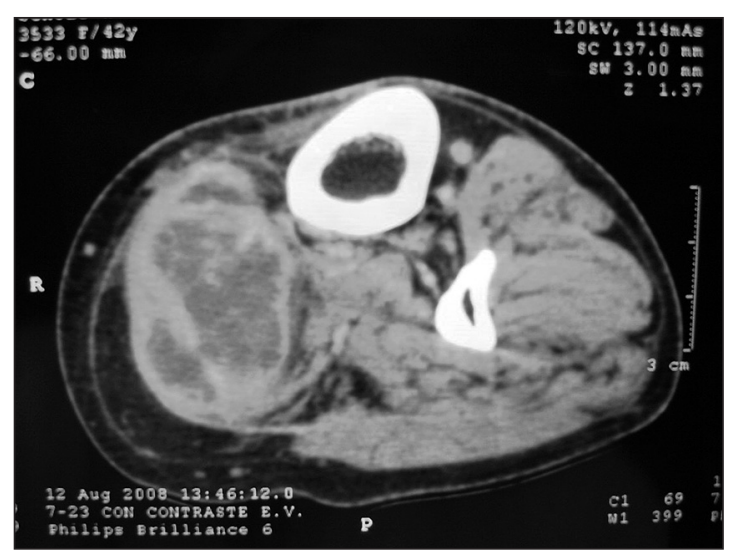

Figura 1. TC de la pierna derecha con contraste IV, corte transversal. musculares y la electromiografía por lo general son normales. El diagnóstico finalmente se realiza con biopsia diferida de una muestra musculocutánea ${ }^{7}$.

El objetivo de este trabajo es dar a conocer una forma de presentación inhabitual de hidatidosis, que se presentó en una paciente del Hospital Base Osorno (HBO), además de revisar el estado del arte de la hidatidosis muscular.

\section{Caso clínico}

Paciente de sexo femenino, 43 años, de zona rural, sin antecedentes mórbidos, que consulta en el servicio de urgencia del HBO por un cuadro de 3 días de evolución caracterizado por aumento de volumen en cara posterointerna de la pierna izquierda, adherido a planos profundos, asociado a edema, calor local y dolor. Se solicita ecodoppler que informa trombosis venosa quística hospitalizándose e iniciándose tratamiento anticoagulante. A los 2 días, por falta de respuesta al tratamiento, se repite eco doppler que muestra en la misma ubicación 2 imágenes tumorales quísticas multiloculadas que disecan la fascia, motivo por el que se suspende la anticoagulación. Se realiza Tomografia Computada (TC) de pierna izquierda que identifica en el borde interno de la región gemelar una masa sólida quística de 6 x 4,5 $\mathrm{x} 3,3 \mathrm{~cm}$ (Figuras 1 y 2). Bajo el diagnóstico de probable sarcoma se deriva a Oncología. A los 21 días de iniciado el cuadro se controla en dicho servicio. Se solicita TC tórax, abdomen y pelvis con contraste, los que descartan presencia de enfermedad a distancia. En los exámenes de laboratorio destaca una PCR de 15,9 mg/L, VHS $48 \mathrm{~mm} /$ hora y eosinófilos de 300 UL. A los 2 meses de iniciado el cuadro se

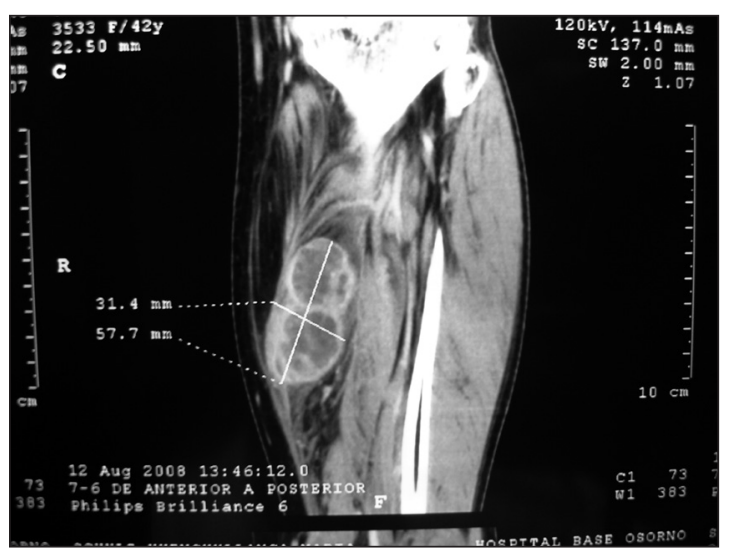

Figura 2. TC de la pierna derecha con contraste IV, corte coronal. 


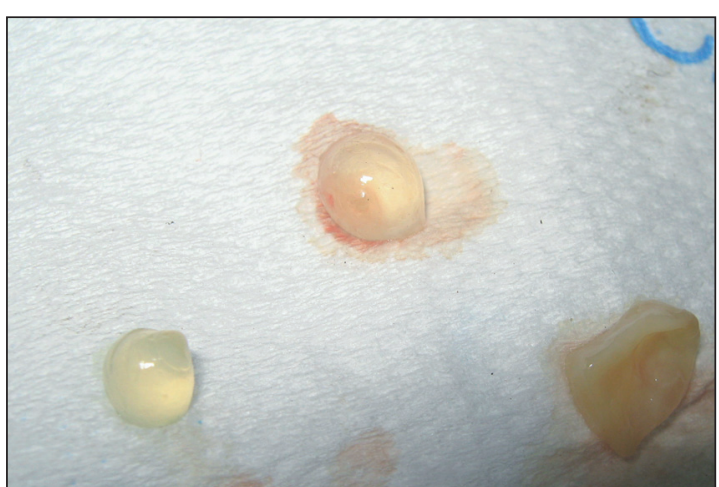

Figura 3. Vesículas hidatídicas eliminadas a través de fístula hidatídico cutánea (foto gentileza de Danitza Oyarzún Tejeda).

practica biopsia incisional de la lesión informando la presencia de una fasceítis eosinofílica por lo cual se inicia tratamiento corticoidal por 4 semanas. Al control del mes siguiente, se evidencia regresión parcial de la lesión y la herida se encontraba parcialmente dehiscente. A los 2 meses siguientes se controla con nuevo TC, evidenciando aumento del tamaño de la lesión $(8,1 \mathrm{~cm})$. En esta consulta la paciente relata el drenaje espontáneo de la misma y trae una fotografía de vesículas drenadas con un aspecto muy sugerente de origen hidatídico (Figura 3). Se realiza IgG para hidatidosis que resulta positiva. El 23 de marzo de 2009 se practica quistectomía. La biopsia diferida informa la presencia de quiste hidatídico de $4,5 \mathrm{~cm}$ encapsulado (Figura 4).

\section{Discusión}

La hidatidosis musculoesquelética puede llegar a ser un 5\% de las hidatidosis, este porcentaje está dado más por la ubicación ósea que la muscular ${ }^{5,8,9}$. La hidatidosis muscular puede presentarse de forma primaria (más frecuente) así como secundaria ${ }^{4,9,10}$. Las regiones musculares preferentemente comprometidas son: cuello, tronco y zona proximal de las extremidades $^{4}$. En la literatura internacional desde el año 1967 hasta la fecha, sólo hay 3 casos publicados de hidatidosis en la pierna ${ }^{11-13}$.

La hidatidosis muscular se presenta generalmente en áreas endémicas, como la nuestra. Simula un tumor de partes blandas que desplaza los tejidos vecinos, en ausencia de un antecedente traumático y/o quirúrgico previo ${ }^{4}$. Su crecimiento y posterior desarrollo es lento y complejo, debido a la contracción muscular intermitente y a la acidez láctica presente ${ }^{4,10}$. Los síntomas, dolor y aumento de volumen, son secundarios a la compresión; en caso de com-

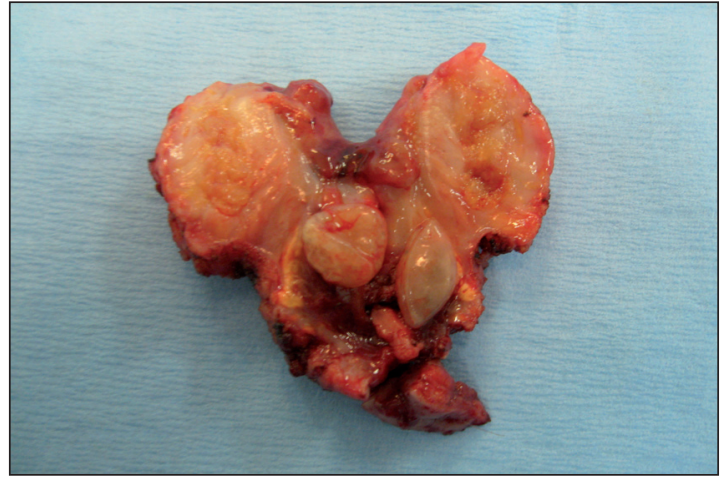

Figura 4. Pieza postoperatoria. Resección de paredes de quiste hidatídico de la pierna, se aprecian 2 vesículas no viables.

plicación se pueden asociar signos inflamatorios ${ }^{4,14}$. El diagnóstico, al igual que en otras localizaciones es por serología e imagenología (ultrasonido, TC y RNM ${ }^{10}$. El test de ELISA tiene una baja sensibilidad y especificidad en hidatidosis extrahepática 1 legando a un 50 y $25 \%$ respectivamente, por lo que la negatividad de estas pruebas no descarta el diagnóstico ${ }^{15}$. La sensibilidad de la ultrasonografía va de un $95 \%$ a un $100 \%$. Los signos clásicos a la ecografía de un quiste hidatídico de cualquier ubicación son: tumor quístico, multiloculado con vesículas hijas en el interior sin invasión a estructuras vecinas $^{8,10}$. También puede aparecer como una masa sólida simulando un granuloma o un tumor, siendo importante para su diferenciación el identificar la presencia de calcificación de la pared.

La utilidad del TC está en definir mejor la localización quística y descartar compromiso de órganos vecinos $^{15}$. En el TC se puede ver un quiste esférico u ovalado con vesículas hijas en el interior y calcificación total o parcial de las paredes. En ocasiones, los hallazgos pueden no ser patognomónicos y simular un quiste congénito o un tumor o metástasis ${ }^{9}$. La RNM muestra una lesión quística con vesículas hijas, con paredes rodeadas por un halo de menor densidad en T1 y T2. En T2 el líquido hidatídico capta contraste $^{9}$. En varias ocasiones la imagenología no es patognomónica y la serología es negativa por lo que el diagnóstico es intra o postoperatorio ${ }^{15,16}$.

El diagnóstico diferencial puede ser un absceso, un hematoma, un granuloma, una metástasis y otros tumores quísticos ${ }^{3}$. La literatura no plantea dentro del diagnóstico diferencial la fasceítis eosinofílica.

En el caso clínico se planteó como primera posibilidad diagnóstica un sarcoma de partes blandas. La presentación clínica dada por dolor, edema, la ausencia de vesículas hijas y/o calcificaciónes de las paredes quísticas en el estudio imagenológico y el 
casi nulo reporte de hidatidosis de esta localización, llevaron a que no se planteara la hidatidosis como diagnóstico diferencial.

Dentro de las posibilidades terapéuticas de la hidatidosis muscular se encuentran la periquistectomía total o parcial y el drenaje percutáneo, ambas en asociación o no a albendazol ${ }^{8-10,17}$. El tratamiento clásico es la cirugía. El manejo percutáneo a tenido éxito en quistes hepáticos, pulmonares, renales y en otras zonas como parótida y órbita. Hay aislados casos de manejo de hidatidosis muscular con drenaje percutáneo, con controversiales resultados 9 .

En nuestra paciente el hemograma no informó eosinofília. La imagenología tampoco mostró compromiso de la fascia muscular. La biopsia que informó una fasceítis eosinofílica y la respuesta parcial al tratamiento corticoidal asociado a la edad, sexo de la paciente y a la localización tumoral, llevaron a creer que el diagnóstico era correcto. Fue el drenaje espontáneo de las vesículas hidatídicas lo que nos aclaró el diagnóstico definitivo.

Actualmente la paciente se encuentra en buenas condiciones generales, con su herida operatoria cicatrizada, sin evidencia de enfermedad, en seguimiento.

Como conclusión, creemos que el diagnóstico de hidatidosis pudiera ser considerado frente a un tumor de partes blandas de patrón quístico o mixto, de crecimiento lento en un paciente rural, especialmente en zonas endémicas de hidatidosis.

\section{Referencias}

1. Manterola C, Vial M, Fonseca F, Carrasco R, Bustos L, Muñoz S, y col. Hidatidosis abdominal de localización extrahepatica. Características clínicas y evolución de una serie de casos. Rev Chil Cir 2002; 54: 128-134.

2. Sayek I, Tirnaksiz M, Dogan R. Cystic Hydatid Disease: Current Trends in Diagnosis and Management. Surg Today 2004; 34: 987-996.

3. Engin G, Acunaş B, Rozanes I, Acunaş G. Hydatid disease with unusual localization. Eur Radiol 2000; 10: 1904-1912.

4. Kazakos C, Galanis V, Verettas D, Polychronidis A, Simopoulos C. Primary Hydatid Disease in Femoral Muscles. J Int Med Res 2005; 33: 703-706.
5. Uysal M, Kilic D, Findikcioglu A, Tarim A, Kocer N. Coexistence in unusual locations of hydatid cysts: thigh, breast and lung involvement. Int J Infect Dis 2007; 11: 470-472.

6. Prousalidis J, Tzardinoglou K, Sgouradis L, Katsohis C, Aletras H. Uncommon Sites of Hydatid Disease. World J Surg 1998; 22: 17-22.

7. Bischoff L, Derk C. Eosinophilic fasciitis: demographics, disease pattern and response to treatment: report of 12 cases and review of the literature. Int J Dermatol 2008; 47: 29-35.

8. Alexiadis G, Lambropoulou M, Deftereos S, Papadopoulos N, Manavis J. Primary muscular hydatidosis. US, CT and MR findings. Acta Radiol 2002; 43: 428430 .

9. Akhan O, Gumus B, Akinci D, Karcaaltincaba M, Ozmen M. Diagnosis and percutaneous treatment of softtissue hydatid cysts. Cardiovasc Intervent Radiol, 2007; 30: 419-425.

10. Koc Z, Ağildere A, Yalcin O, Pourbagher A, Pourbagher M. Primary hydatid cyst in the anterior thigh: Sonographic findings. J Clin Ultrasound 2004; 32: 358-360.

11. Hissamudin, Maheshwari KL. Hydatid cyst of calf muscles. J Indian Med Assoc 1967; 49: 235-236.

12. Kühne R, Stäubli M, Schmid W. Echinococcosis a differential diagnosis of calf swelling. Praxis 2005; 94: 117-118.

13. Erol B, Tetik C, Altun E, Soysal A, Bakir M. Hydatid cyst presenting as a soft-tissue calf mass in a child. Eur J Pediatr Surg 2007; 17: 55-58.

14. Kayikçioğlu A, Karamürsel S. Primary hydatidosis of the thigh. Plast Reconstr Surg 1999; 104: 2341-2342.

15. Orhan Z, Kara H, Tuzuner T, Sencan I, Alper M. Primary subcutaneous cyst hydatic disease in proximal thigh: an unusual localisation: a case report. BMC Musculoskelet Disord 2003; 4: 25.

16. Thursky K, Torresi J. Primary Muscle Hydatidosis of the Thigh: Management of a Complicated Case with Combination Adjunctive Albendazole and Praziquantel Chemotherapy. Clin Infect Dis 2001; 32: 65-68.

17. Yüksel B, Akbulut A, Hengirmen S. A minimally invasive treatment option in primary muscular hydatid cyst: report of 2 cases. Can J Surg 2008; 51: 153-154.

18. Hamamci E, Besim H, Korkmaz A. Unusual locations of hydatid disease and surgical approach. ANZ J Surg 2004; 74: 356-360. 